\title{
Educar en competencias
}

Nancy Gabriela Galván Estrada

Concepto y sentido

¿Qué significa educar en competencias?

¿Cómo y por qué?

¿Cuál debe ser el papel de la escuela y del docente? ¿Qué retos se enfrentan?

F stas y otras interrogantes enfrenté cuando comencé a transitar por

E el camino de Formación Docente en el ámbito de las competencias; en primera instancia cuando tomé el Programa de Formación Docente de Educación Media Superior (PROFORDEMS) que ofrece la Subsecretaría de Educación Media Superior de la SEP junto con ANUIES, y más tarde el Diplomado que ofrece la Universidad a través de la Dirección General de Docencia de Pregrado y la Unidad de Formación Académica de Profesores.

Reconozco que las respuestas son múltiples y variadas, así como las consideraciones que se pudieran hacer al respecto, por lo que la intención de este artículo es compartir un punto de vista, una reflexión respecto al papel que tiene la escuela como formadora de jóvenes adolescentes, y también respecto al perfil deseable en los docentes, así como los retos a enfrentar con esta nueva tendencia educativa.

Defino las competencias como:

$1^{\mathrm{O}} \mathrm{El}$ conjunto de saberes integrados puestos en acción. Estamos hablando de desempeños idóneos donde unimos el conocimiento, las habilidades, los valores y la actitud.

$2^{\circ}$ Con sentido y utilidad para el estudiante. Esto nos lleva a pensar en un aprendizaje significativo.

$3^{\mathrm{o}}$ Y adecuados a un contexto. Situamos/ubicamos al sujeto /estudiante en la realidad que vive, lo que nos lleva a pensar en el concepto de aprendizaje situado y pertinente.

\section{Cambios y nuevos paradigmas}

Desarrollar competencias en el estudiante representa una visión de formación integral. Como docentes debemos adaptar las exigencias del mundo actual y orientarlo a facilitar el aprendizaje y el entrenamiento en habilidades y estrategias para que los jóvenes aprendan a enfrentar la vida, así los docentes facilitan la construcción de su conocimiento, estimulando su pensamiento autónomo, creativo, crítico y reflexivo.

Lo anteriormente mencionado implica no sólo una educación centrada en el estudiante, sino también una transformación del papel docente 
en la que se ponen en juego las propias competencias para planear, impartir, construir escenarios y ambientes educativos, así como evaluar y retroalimentar todo el proceso que conlleva la enseñanza y el aprendizaje.

Gavilán y D’Onofrio (2008) en su artículo “Re-pensar al adolescente de hoy y re-crear la escuela" señalan que éste es el núcleo central de reencuentro con la posmodernidad; por lo que los docentes que quieran formar estudiantes competentes deberán ver en clases en el aula un taller de formación en el que habrán de trabajar por dar a los jóvenes las herramientas necesarias para enfrentar el mundo, madurar y prepararlos para integrarse en la sociedad de una manera mucho más efectiva.

El doctor Miguel Székely Pardo ${ }^{1}$ ha señalado que la Educación Media Superior (EMS) representa un terreno de grandes retos y oportunidades para el país, pues este nivel presenta las mayores carencias de todo el sistema educativo, por ejemplo en el año 2007: un índice de deserción de cerca de 40 por ciento en el que se atribuía como causa principal, antes que la falta de recursos económicos, a que los propios jóvenes manifestaban que la escuela no les gustaba, no les servía, o no se adecuaba a sus intereses y necesidades. ¿Cómo es posible esto?, la respuesta no es simple, dentro de la literatura especializada se encuentra que actualmente el vínculo que se vive entre el adolescente y la escuela es cada vez más distante porque se tiene una escuela moderna que atiende a adolescentes posmodernos; es decir, se observan estudiantes con conductas y actitudes que llaman la atención cada vez más por el desinterés que muestran hacia los estudios, su falta de motivación, compromiso y responsabilidad.

¿Qué está sucediendo?, ¿hasta dónde es veraz? Lo ignoro a ciencia cierta, pero tal vez si nos pusiéramos a indagar un poco más en todo esto, encontraríamos que una parte de verdad toca en algo a la escuela y otro tanto a los docentes, aunque seguramente encontraríamos también que existen otros elementos conectados con procesos relacionados con una dinámica familiar particular y social que viven algunos jóvenes.

\section{El papel de la escuela}

Los jóvenes se encuentran rodeados de información que les llega a través de distintos medios: han nacido con la tecnología en sus manos, están imbuidos de una cultura de la imagen que les absorbe y les fascina: tienen la computadora, los videojuegos, la televisión, la Internet, el celular, el Ipod y otras cosas más al alcance de sus manos. Para ellos apretar un botón resulta simple y acceden fácilmente a la información, pero hablando dentro del aula ¿que hacen en ella? El docente tiene un nuevo reto: enseñar a utilizar, procesar e integrar información útil y de fuente fidedigna para lograr un aprendizaje significativo y no dejar que el estudiante sólo "junte" información y haga el sabroso "copiar y pegar".

¿Cuál debe ser el papel del docente? A los jóvenes ya no le gusta memorizar, repetir o escuchar solamente en una clase, esperan algo más, algo que los motive y los ponga en acción a la vez que les resulte interesante. Los estudiantes esperan que la escuela se transforme y les resulte un punto de encuentro y re-encuentro entre adolescentes y adultos; les ofrezca una mirada diferente frente al mundo que viven (lo cual en ocasiones no es muy alentador), promueva
Ex Subsecretario de Educación Media Superior, que inauguró en septiembre de 2009 el X Coloquio Nacional de Formación Docente del Nivel Medio Superior, en la Universidad Juárez del Estado de Durango. 
una cultura del esfuerzo que los motive a aprender significativamente y con placer, dedicando su tiempo al estudio, así como a la búsqueda del saber y del hacer a través de la resolución de diferentes situaciones que les formen su carácter, pensamiento y personalidad.

$\mathrm{Al}$ estar hablando de competencias, conviene pensar en una escuela que fomente una cultura emprendedora y de proyectos, que presente valores claros y humanistas y eduque con el ejemplo, [por ejemplo como lo hace el Centro de Educación Media, específicamente el Bachillerato Internacional mediante el proyecto CAS (creatividad, acción y servicio)]. Los jóvenes necesitan una escuela vinculada con la sociedad, donde puedan participar en proyectos de servicio social y proyecten toda su creatividad estimulando su compromiso consigo mismos con los demás, reconociendo en esto la oportunidad para encontrar su vocación o perfilar su proyecto de vida interactuando con otros y enriqueciendo su mundo interior.

\section{Perfil del docente}

Si cambiamos de paradigma educativo y pasamos ahora a centrarnos más que en la enseñanza, en que el estudiante aprenda, éste será el punto central de la obra educativa.

El docente actual deberá ser un formador y ejemplo vivo competente para que con sus acciones y actitudes transmita valores y sea un verdadero líder que dé testimonio de congruencia y autenticidad; se conozca a sí mismo y asuma sus fortalezas y debilidades transformándolas en áreas de oportunidad para el cambio y, con ello, ajustar las nuevas demandas de este siglo buscando siempre estar al día para ofrecer lo mejor de sí.

Un docente debe ser creativo y aplicar la innovación dentro del aula para gestionar el trabajo participativo y colaborativo, pero también sacarlos de ella para llevarlos a otros espacios de acción e investigación donde interactúen con diversas fuentes de información y generen productos de aprendizaje. Entender cómo es la nueva generación de adolescentes que tenemos, estar dispuesto y actualizado, tener un sentido de compromiso y espíritu de servicio, vocación y valores, manejar las tecnologías de la información y la comunicación, y ser constructor y generador de nuevas prácticas y estrategias de enseñanza-aprendizaje, así como de procesos de evaluación centrados en competencias son algunos de los rasgos que debe tener un docente formador en este enfoque.

Un docente que inspire, mueva, cuide, anime y confíe en sus alumnos, para que lleguen a ser y hacer todo lo que son capaces lo lograrán si así lo desean, puesto que tienen el potencial.

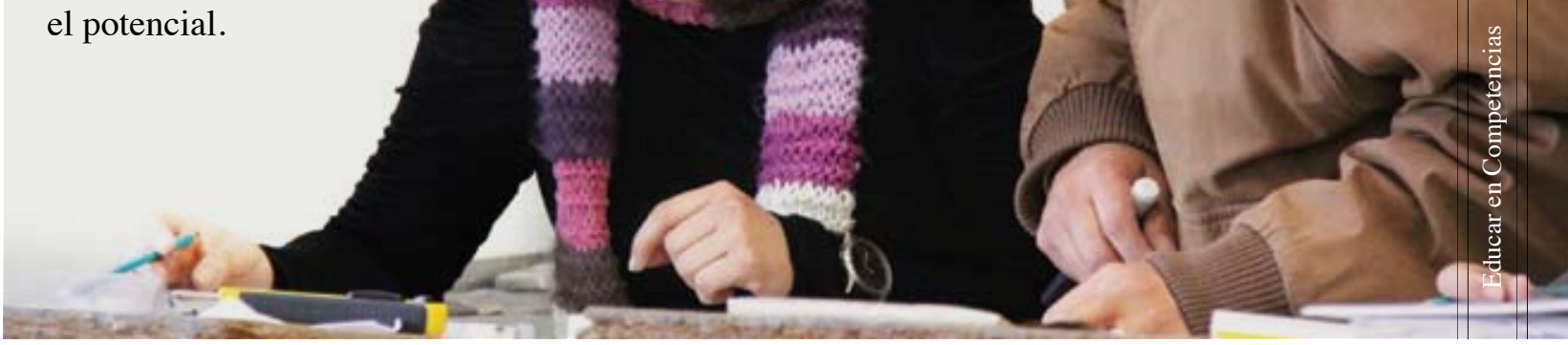




\section{Los retos}

Los retos para la Educación Media Superior, considerando la reforma curricular que tenemos en puerta -tanto a nivel nacional como institucional-, se pueden englobar en: transformación de conductas, actitudes, valores, paradigmas, metodologías y estrategias de intervención en el aula, entendiendo que transformar no es anular lo que ya se domina, sino re-aprender, desaprender, aderezar y reajustar.

Como docentes formadores en competencias debemos:

Observar las bondades y beneficios de los cambios porque nuestros estudiantes se merecen profesores del siglo XXI.

Conocer nuestro Modelo Educativo Institucional y la propuesta del Modelo Curricular por Competencias.

Apoyar con visión y convicción a la Institución, creyendo que es posible desarrollar competencias y que no son una moda pasajera o una imposición, sino una necesidad actual.

Vencer las resistencias y centrarnos en hacer de nuestros estudiantes seres críticos, reflexivos y conscientes de sí mismos y de su entorno, colaborativos, autónomos, responsables, comunicativos y partícipes en su sociedad.

La tarea será encontrar los "cómos" y cada docente tendrá que encontrar los propios, buscando, leyendo, experimentando con aciertos y desaciertos, y aprendiendo también a través de los Diplomados que ofrece la Unidad de Formación Académica de Profesores en nuestra Institución.

El compromiso es alto, se requiere disposición al cambio y contribuir al trabajo que comienza, la tarea es ardua, pero de beneficio para todos.

Trabajemos siendo puentes para llevar a nuestros estudiantes hacia el desarrollo de sus competencias, acompañándoles y construyendo los andamiajes que necesitan para que asciendan y aprendan a volar con sus propias alas.

"Si un docente camina, hará caminar a sus estudiantes", pero, si el estudiante corre... ¿Qué hará el docente...?

\section{Bibliografía}

De Martin Rojo, Elena. (2006). Tender puentes. Una perspectiva para educar y convivir con los adolescentes. España: Octaedro.

Gavilán María de los Ángeles y D’Onofrio, Silvia. Art. Re-pensar al adolescente de hoy y re-crear la escuela. Consultado el 15 de agosto de 2009 en: http://www.educared.org.ar/vicaria/adjuntos/tema-mes/Conf-Adolescencia.pdf

Subsecretaría de Educación Media Superior. (2008). Doc. Reforma Integral de la Educación Media Superior en México. La creación de un Sistema Nacional de Bachillerato en un marco de diversidad. México: SEP 